\title{
A (RE)DESCOBERTA DE SI: IMPLICAÇÕES E APRENDIZAGENS PRODUZIDAS A PARTIR DO PROJETO “CUIDADORES QUE DANÇAM”
}

\author{
RE-DISCOVERING ONESELF: IMPLICATIONS AND LEARNING PRODUCED IN \\ THE PROJECT "CAREGIVERS WHO DANCE"
}

\author{
EL (RE)DESCUBRIMIENTO DE SI MISMO: IMPLICACIONES Y APRENDIZAJES \\ PRODUCIDOS A PARTIR DEL PROYECTO "CUIDADORES QUE BAILAN"
}

\author{
Erineusa Maria da Silva*, Bianca Carminati Schmidt*, \\ Maria das Graças Carvalho Silva de Sá*, José Francisco Chicon*
}

\begin{abstract}
Palavras chave:
Família.

Cuidadores.

Terapia através da

dança.

Pessoas com

deficiência.

Resumo: 0 estudo em tela objetiva compreender como o projeto de extensão "Cuidadores que dançam" tem sido ocupado/vivenciado pelas participantes a partir da análise das implicações e aprendizagens produzidas, em especial, sobre o cuidado de si nesse espaço. Caracteriza-se como pesquisa qualitativa com caráter exploratório e descritivo. As participantes foram 15 mães e/ou responsáveis que cuidam de pessoas com deficiência intelectual e que estão inseridas no projeto. Conclui que o espaço/tempo da vivência no projeto estimulou as participantes a reafirmar o seu papel social para além do ser cuidadora de pessoa com deficiência, descobrindo-se capazes de experimentar seus limites e possibilidades na vida e na dança.
\end{abstract}

Keywords:

Family.

Caregivers

Dance therapy.

Disabled persons.

Palabras clave:

Familia.

Cuidadores.

Terapia a través de

la danza.

Personas con

discapacidad.

Abstract: This study aims to understand how the extension project "Caregivers who dance" has been occupied/experienced by women participants based on analyses of implications and learnings produced and specially of self-care in that space. This is a qualitative, exploratory and descriptive study. Participants included fifteen mothers and/ or guardians who care for people with intellectual disabilities. It concludes that the spacetime of the experience in the project encouraged participants to reassert their social role beyond that of caregivers of disabled people, as they discovered themselves to be able to experience their limits and possibilities in both life and dance.

Resumen: El estudio intenta comprender cómo el proyecto de extensión "Cuidadores que bailan" ha sido ocupado/experimentado por las participantes a partir del análisis de las implicaciones y aprendizajes producidos, especialmente sobre el cuidado de sí mismo en ese espacio. Se caracteriza como investigación cualitativa de carácter exploratorio y descriptivo. Las participantes fueron 15 madres y/o responsables que cuidan a personas con discapacidad intelectual y que están inseridas en el proyecto. Concluye que el espacio/ tiempo de la experiencia en el proyecto estimuló a las participantes a reafirmar su papel social más allá del ser cuidadoras de una persona con discapacidad, descubriéndose como capaces de probar sus límites y posibilidades en la vida y en la danza.
*Universidade Federal do Espírito Santo. Vitoria, ES, Brasil. E-mail: erineusams@yahoo.com.br

Recebido em: 09-12-2015 Aprovado em: 10-05-2016 (c) (1) (8) Licence 


\section{INTRODUÇÃO}

É inegável que as pesquisas na área de Educação Especial/Educação Física Adaptada têm se ampliado significativamente nos últimos anos. No entanto, ao realizar uma revisão de literatura sobre o tema, observamos que muitos desses estudos carecem de se apropriar de uma compreensão mais ampliada sobre o contexto de pessoas com deficiência. Dito de outra maneira, pensar sobre todo o contexto que envolve essa discussão significa também incluir a família da pessoa com deficiência, temática essa pouco abordada no campo educacional, sobre a qual nos propusemos dar visibilidade neste artigo.

Nesse percurso, encontramos poucos estudos referentes à família de pessoas com deficiência que investigam os sentimentos e a reconfiguração de vida experimentados pelos familiares ao se depararem com os desafios que envolvem o contexto da deficiência. As produções nesse sentido são escassas. O livro intitulado Os deficientes e seus pais, de Leo Buscaglia (1993), representa uma referência clássica a essa temática. Aborda os sentimentos vividos pelos familiares e a forma como a família se organiza após a chegada de um membro com deficiência.

Entre outras produções encontradas sobre essa temática, está a de Brito e Dessen (1999), que objetivou descrever estudos sobre as interações e relações desenvolvidas entre a criança deficiente e sua família; e a de Nunes, Silva e Aiello (2008), em que os autores analisam a importância do pai e do irmão para o desenvolvimento da pessoa com deficiência. No geral, as pesquisas discutem sobre a participação da família no processo de escolarização da pessoa com deficiência e sua importância para o desenvolvimento do indivíduo no meio social. Porém, acabam não discutindo a família propriamente dita, seus sentimentos e reconfigurações para lidar com o contexto que envolve a deficiência.

Na direção de discutir essa reconfiguração familiar, retomamos Buscaglia (1993), que nos aponta que a família é envolvida no processo de vida da pessoa com deficiência desde 0 momento em que toma ciência dessa situação, mas é com o nascimento de um membro com deficiência na família que, de fato, o papel de cada envolvido é reconfigurado. Entretanto, de acordo com Welter et al. (2008), essas reconfigurações ocorrem principalmente na vida das mulheres que, normalmente, assumem/são convocadas a responsabilidade de cuidar do(a) filho(a ) com deficiência.

Por outro lado, dificilmente esses familiares encontram atividades sistematizadas apropriadas para si, ofertadas simultaneamente às atividades dos(as) filhos(as), dificultando que eles realizem ações de seu interesse e que se direcionem ao cuidado de si em algum momento.

O cuidado de si é aqui compreendido como o reconhecimento da importância de o ser humano constituir seu corpo como um lugar de cuidado, como merecedor de cuidados e de tempo para si na mesma medida em que cuida do outro e oferece seu tempo ao outro. Segundo Boff (2011, p. 2), o cuidado "É o sentimento que torna pessoas, coisas e situações importantes para nós". Logo, o cuidado de si é concebido como o ato pelo qual nos tornamos importantes para nós mesmos.

Essa situação de ausência de atividades sistematizadas voltadas para o cuidado de si apresentava-se recorrente em relação às mães que levavam seus filhos para realizarem 
práticas corporais no Laboratório de Educação Física Adaptada, Centro de Educação Física e Desportos, Universidade Federal do Espírito Santo (Laefa/Cefd/Ufes). As cuidadoras ${ }^{1}$ dos 40 adolescentes, jovens e adultos com deficiência intelectual, matriculados no projeto de extensão "Prática pedagógica de Educação Física adaptada para pessoas com deficiência", aguardavam os filhos realizarem diversas práticas corporais e, nesse tempo de espera, quando poderiam realizar alguma atividade voltada para o cuidado de si, não encontravam nenhuma prática sistematizada que pudesse atender a seu desejo e necessidade.

Preocupados em mudar esse cenário que nos angustiava e, também, em virtude de pedidos das cuidadoras, elaboramos o projeto de extensão denominado "Cuidadores que dançam" - direcionado às cuidadoras desses adolescentes, jovens e adultos que aguardavam seus filhos. ${ }^{2}$ O projeto, em funcionamento desde 2011, tem como objetivo propiciar um espaço/ tempo para que as participantes tenham um momento de descoberta de si em contexto de descontração e aprendizado a partir das diversas formas de dança. Buscamos oferecer uma proposta diferenciada do que comumente é disponibilizado a esse grupo em alguns locais de atendimento à pessoa com deficência. A Associação de Pais e Amigos dos Excepcionais (Apae), frequentada pelas participantes do projeto, por exemplo, desenvolve atividade que tem como foco a costura ou o tricô, porém, nada que promova o cuidado e a (re)descoberta de si como pessoa, para além de ser cuidadora de filhos e parentes com deficiência. Pensando em uma sociedade que se pressupõe solidária, o cuidado com o e do outro é fundamental. No entanto, observamos que, no caso de nossas participantes, o cuidado com o e do outro tem sido mais exercido que o cuidado de si.

Nessa linha, a dança, com seu forte potencial para ampliar a expressão e a cultura corporal, pareceu-nos um conhecimento importante e mobilizador naquele momento. Trabalhamos o conhecimento da dança, orientando-nos pela proposição apontada por Souza (2004, p. 361), de que:

Não adianta propugnar o 'ser livre para criar, pensar e sentir' se não se contribui para ampliar as potencialidades de se expressar essa liberdade através do corpo que por sua vez se insere em um contexto cultural. Assim, o conhecimento em dança articula-se com o conhecimento para a dança, abrindo espaço para a criação e transformação de identidades culturais.

Nosso intuito foi de que, além da técnica, as participantes pudessem aprender a respeito da história da dança, suas origens e relações com as diversas culturas, além de adquirirem um olhar sobre si como ser dançante, cultivando o gosto de se cuidar não apenas na dimensão física do corpo. Acreditamos que a dança, mediada pela ação docente, poderia ser uma prática potencializadora de conscientização corporal, de cuidado de si e mantenedora da solidariedade do cuidado com o e do outro.

De acordo com Melo (2005, p. 175), a consciência corporal advém das reflexões filosóficas sobre a noção de corpo que nos traz a ideia de "[...] refletirmos sobre nossa existência corpórea no mundo e as relações entre ambos estabelecidas [...]". Ademais, o entendimento oriundo da incorporação pela Educação Física, na década de 1980, das práticas corporais alternativas, como a bioenergética, a antiginástica, gerou um conceito de consciência corporal, por nós aderido, que se vincula às questões de ordem sensitiva. A sensação e a atenção ao

1 Passamos a chamar as participantes do projeto de cuidadoras, pois, desde o início, apenas três pais frequentaram em momentos distintos o projeto e também pelo fato de as participantes desta pesquisa terem sido apenas as mães e irmãs dos jovens e adultos com deficiência. 
corpo em movimento são compreendidas como "[...] as bases para ser estabelecido um diálogo das pessoas com seu próprio corpo" (MELO, 2005, p. 175), pois a consciência corporal, em nosso entendimento, deve refletir a aceitação e consolidação do corpo que somos.

É notório, em nosso meio social, que a sociedade oferece práticas corporais para o modelo de corpo preestabelecido por ela: mais jovem, forte e saudável. Percebemos, então, uma falta de práticas voltadas para corpos que não se encaixam nesse modelo de corpo definido pela sociedade, corpos esses que também têm necessidade de se cuidar e se expressar (MELO; ANTUNES; SCHNEIDER, 2005). Quando se trata de familiares de pessoas com deficiência, essa falta de práticas é ainda maior, pois muitos deles não têm condições financeiras e, ao mesmo tempo, não têm quem cuide de seus filhos para que possam realizar outras atividades.

Com base nesses apontamentos, decidimos, então, compreender de forma mais rigorosa como esse espaço/tempo do projeto tem sido ocupado/vivenciado pelas cuidadoras, e também investigamos quais foram as possíveis aprendizagens e as mudanças percebidas sobre o cuidado de si na vida dessas cuidadoras ao longo da experiência produzida.

Para responder a essas duas questões, traçamos como objetivo analisar o projeto de extensão "Cuidadores que dançam" a partir do olhar das cuidadoras, especialmente buscando evidenciar as aprendizagens e mudanças percebidas por elas sobre o cuidado de si ao longo desse processo. Especificamente, procuramos: a) problematizar as mudanças ocorridas na vida das mulheres com o nascimento do(a) filho(a) deficiente; b) problematizar a relação estabelecida entre as mulheres com o próprio corpo e com o corpo do outro; c) dissertar sobre as possíveis aprendizagens promovidas pela dança na vida das cuidadoras.

\section{CAMINHOS PERCORRIDOS}

Neste estudo, realizamos uma pesquisa ${ }^{3}$ de natureza qualitativa, descritiva e exploratória com vistas a não somente entender o objeto estudado, mas, também, e principalmente, aprofundarmo-nos sobre a problemática, tornando-a mais evidente, a fim de melhor contextualizar a população da experiência elencada (NEVES, 1996).

Assim, pretendemos nos familiarizar a respeito do processo educativo vivido pelas pesquisadas, mapeando-o e descrevendo-o, com a finalidade de produzir novos conceitos a partir dessa temática e ampliar a produção de conhecimentos nessa área que é tão pouco explorada, abrindo frentes subsequentes de pesquisas concebidas com maior compreensão e precisão (GIL, 1999).

A produção dos dados ocorreu durante o projeto, de 2011/2 até o semestre 2013/1, período em que foram efetivados 64 encontros. As aulas eram realizadas todas as quintasfeiras, das 14 às 16h, no Laefa. Durante as aulas buscamos proporcionar conhecimentos a respeito da linguagem das danças de salão e das danças populares brasileiras, tanto no que se refere aos seus aspectos gestuais, como os histórico-culturais. A aula normalmente se orientava por três momentos: no primeiro momento sempre trazíamos uma dinâmica de grupo ou dinâmica com teatralização que preparasse os participantes para o ritmo que vivenciariam

3 Informamos que, apesar de o projeto de pesquisa não ter sido enviado ao Comitê de Ética em Pesquisa, seguimos com rigor os preceitos éticos da Resolução 466/2012, que trata de pesquisa envolvendo seres humanos. Todas as participantes assinaram o Termo de Consentimento 
no dia. Na sequência conversávamos a respeito de aspectos histórico-culturais da forma de dança a ser tratada no dia e depois oportunizávamos a vivência do ritmo, seguida por uma atividade de relaxamento. Ao final fazíamos uma avaliação da aula, quando as cuidadoras podiam expor suas opiniões e propor mudanças; isso auxiliava a bolsista e os voluntários na preparação das aulas seguintes.

Como instrumentos para a recolha de dados, utilizamos o diário de bordo das aulas ministradas e uma entrevista com roteiro semiestruturado. 0 diário de bordo foi realizado com todas as 15 participantes do projeto, sendo as entrevistas realizadas com cinco respondentes. Todas as participantes da pesquisa acompanhavam/cuidavam de adolescentes, jovens e adultos com deficiência intelectual matriculados no Laefa/Cefd/Ufes e tinham idade entre $25 \mathrm{e}$ 60 anos. Cumpre destacar que todas as cuidadoras foram convidadas a participar da entrevista, mas, tendo em vista diversas situações, como disponibilidade de tempo, predisposição de falar sobre si, timidez, dentre outras, apenas cinco delas se dispuseram a ser entrevistadas.

Tanto as análises prévias do diário de bordo como as entrevistas se guiaram por uma perspectiva interpretativa, utilizando elementos da análise de conteúdos especialmente a partir da realização de categorizações do observado e do resultado das entrevistas (BARDIN, 2009). Trabalhamos as seguintes categorias: a) a mulher à frente do cuidado: do nascimento ao cuidado cotidiano; b) relação com o próprio corpo, o cuidado de si e do outro; c) aprendizagens em dança. Essas categorias, apesar de não serem apresentadas como itens específicos nas discussões que seguem, compõem as reflexões apresentadas em cada um, como se vê.

\section{A MULHER, 0 NASCIMENTO E O CUIDADO COTIDIANO DOS(AS) FILHOS(AS)}

Percebemos que é na família que ocorrem imbricamentos valorativos que marcam as pessoas quanto a sua identidade, ${ }^{4}$ os espaços sociais e os papéis que cada indivíduo representa. A função da mulher, no caso de presença de filhos com deficiência, exacerba-se, bem como sua atuação com o cuidado destes, levando-a, recorrentemente, a abdicar de sua vida profissional. Mesmo com a inserção da mulher no mundo do trabalho, o cuidado da casa e dos filhos ainda é um papel social e culturalmente designado à mulher (D'ÁVILA, 2003).

A partir dos dados de entrevistas e comentários feitos durante as aulas, registrados no diário de bordo, percebemos que é incumbida à mulher uma grande sobrecarga emocional e física relacionada com o cuidado: é a mãe (ou ainda a irmã ou tia) que passa a maior parte de seu tempo se dedicando à pessoa com deficiência, levando-a a médicos e clínicas. Assim, ela acaba por se colocar em segundo plano, não tendo tempo para realizar alguma atividade de seu interesse, mesmo a profissional.

A entrevistada Joelma confirma essa situação, dizendo que somente após a aposentadoria de seu marido ela começou a pensar em estudar. Em suas palavras: "No ano que vem, eu pretendo fazer uma faculdade [...]. Meu esposo vai ficar com meu filho porque agora ele tá aposentado [...]". Já a entrevistada Aylma afirma:

[...] Quando ele nasceu, além da síndrome de Down, ele veio com vários problemas: problemas cardíacos, problema de alergia grave. Passei uma parte, praticamente uns 11 anos da minha vida, em hospitais [...].

4 Entendemos identidade a partir do conceito trazido por Castilho (2005, p. 231) como: "Processo de representação ao mesmo tempo pessoal e coletivo que permite ao sujeito se definir com relação a um 'eu' ou a um 'nós' diferenciando-se do outro ou dos outros". 
Não podemos deixar de citar os sentimentos adquiridos pela família com a chegada de um membro com deficiência. Segundo Lamb e Billings (1997), o nascimento do filho com deficiência causa diversas complicações provenientes de sentimentos de culpa, negação, rejeição e, em consequência, mudanças tanto na relação como na estrutura da família. Os pais acabam por se afastar dessa situação que, por vezes, é encarada como um sofrimento, levando inclusive ao abandono da família. Isso influencia diretamente os sentimentos vividos pelas mães, de forma que tais mudanças afetam principalmente a elas, que, na maioria das vezes, são chamadas a assumir o compromisso e a responsabilidade de cuidar do filho com deficiência.

Especialmente no Brasil, tal situação é adensada por uma carga histórica fortemente patriarcal que naturaliza o lugar da mulher na condição de mãe e de mãe de pessoa com deficiência. Para Badinter (1985), a sociedade ainda delega à mulher o cuidado com o filho, como se ela fosse a única pessoa que apresenta capacidade para assumir essa tarefa. Essa atribuição legitimada socialmente gera na mulher um sentimento de dever, de não se eximir de tal função. Esse cuidado se estende ao acompanhamento integral das atividades que os filhos realizam (médico, fisioterapia e atendimentos em diversos locais).

No caso da mãe de pessoa com deficiência, esse papel é ainda mais exigido, pois os cuidados com os filhos requerem maior atenção e disponibilidade e, com isso, o tempo para si fica exaurido desde 0 aspecto do cuidado de si até no âmbito profissional, quando muitas acabam abandonando sua profissão.

A nossa entrevistada Welida relata:

Antes a minha vida era normal, eu trabalhava fora, só tinha um filho que já ia pra escola. Quando o L. nasceu, de imediato eu não sabia, quando eu descobri a deficiência, foi um choque muito grande. A minha vida mudou totalmente, tive que me dedicar quase que exclusivamente a ele, deixando até de lado o mais velho, com quatro anos. Aí eu tive que reestruturar toda a minha vida. Conciliar o mais velho com as atividades dele, do dia a dia, que era natação, fisioterapia, fonoaudióloga, e também a de dona de casa, porque, além de eu ter os dois, eu não tinha ninguém que fizesse nada na minha casa; eu que fazia tudo.

Outra questão vivida pela família é o desconhecimento ou preconceito sobre as reais capacidades das pessoas com deficiência por parte dos médicos. Esses profissionais, ao fazerem um diagnóstico precipitado e não acompanharem o processo de desenvolvimento desses sujeitos, fomentam uma ideia distorcida da real situação e que, recorrentemente, tornase um diagnóstico carregado pelo indivíduo pelo resto de sua vida. Isso é evidenciado na fala da entrevistada Joelma:

[...] e aquele lado também dos profissionais de Medicina, de achar que, no caso, é uma criança assim, que não iria se desenvolver, que iria ser um vegetal, um vegetativo, sempre no berço. Mas, depois que eu vi o meu filho desenvolvendo, fazendo a fisioterapia, a fonoaudiologia, e esse lado de psicologia, eu vi que ele foi se desenvolvendo normalmente, porém com dificuldades.

A situação relatada por Joelma traz à tona questões importantes. Uma delas é que a falta de informação cria uma nova maneira de tornar a mãe a figura central em relação ao cuidado na família. Por ser ela quem leva a criança ao médico, acaba tendo um conhecimento maior da deficiência do filho, o que a legitima como a principal cuidadora dele na sequência cotidiana dos cuidados. Outra questão é o despreparo dos profissionais de medicina no momento de 
dar a notícia, quando a explicação sobre a deficiência é inadequada ou até mesmo inexistente (BUSCAGLIA, 1993).

Assim, normalmente, a mãe que assume quase completamente o cuidado do filho começa a buscar por ela mesma informações e soluções para as dúvidas e dificuldades que aparecem dia após dia. A mãe Joelma afirma que "[...] foi nos livros que eu vim saber o que que era. O que que eu podia tá fazendo eu fui fazendo". Essa busca que as mães, os pais e ou responsáveis têm que realizar sozinhos revela a ausência de políticas públicas e de espaços que possam dar suporte a essas famílias. Isso faz com que, muitas vezes, as famílias se deparem com situações em que, por não saberem como agir, acabam descuidando da melhor atenção à pessoa com deficiência e aprendendo por ações de ensaio e erro, o que não é o mais aconselhado (MOURA; VALÉRIO, 2003).

\section{RELAÇÃO COM O PRÓPRIO CORPO, O CUIDADO DE SI E DO OUTRO: A DANÇA NES- SE PROCESSO}

Analisando as implicações e aprendizagens produzidas a partir do projeto, notamos que essas mulheres estão resgatando o sentimento de cuidado de si e tomando consciência de seu corpo. A entrevistada Joelma afirma: "[...] nós primeiro temos que nos valorizar [...]. Eu tenho que me sentir bem, a mente, o corpo e cuidar do cabelo. É a autoestima, professora. Nós precisamos, todos nós, dessa autoestima [...]".

As aulas em que havia o "se tocar e tocar o outro" eram trabalhadas por meio de dinâmicas e atividades que estimulavam a expressão corporal individual e coletiva, o dançar sozinha e com outras pessoas, o massagear-se e o massagear a outra foram importantes sob dois aspectos: na percepção de si como pessoa também merecedora de cuidados, e que se descobrindo merecedora é capaz de perceber melhor a importância do cuidado e, portanto, também é capaz de cuidar com maior compaixão do outro; e a descoberta de si como ser dançante.

Quanto ao cuidado de si e do outro, as cuidadoras revelam em seu depoimento que 0 projeto de dança tem se constituído em uma atividade que proporciona melhorias na dimensão física e psicológica das participantes, como anuncia a entrevistada Zenilda:

\footnotetext{
Além de tudo, eu acho que aqui, neste projeto, eu percebo que as pessoas têm um atendimento que influi no lado psicológico até mais do que se tivessem fazendo um atendimento com um psicólogo. Isso eu acho muito interessante. É do corpo, né? Então é do corpo pro mental, de cá pra lá e de lá pra cá [...].
}

De acordo com Pinto (2008), a dança promove diversas melhorias para o ser humano. Dentre elas, destacam-se: aumento da autoestima, determinação de motivação, redução do risco de estresse e depressão. A dança "[...] auxilia na manutenção da saúde psíquica, física e mental melhorando o humor e atuando como terapia" (PINTO, 2008, p. 36).

Durante as aulas, constatamos o quanto a dança influenciou o cuidado de si, não apenas no que diz respeito à realização de atividades para o benefício físico e mental, mas também no momento em que as participantes demonstram preocupação em como estariam vestidas e maquiadas quando anunciávamos que iríamos fazer uma apresentação. Essa preocupação se dava porque elas não queriam "fazer feio" no dia da apresentação. Notamos esse cuidado com a aparência no fragmento extraído do diário de bordo (30-8-2012) abaixo: 
Ao saber que iriam se apresentar no teatro da Ufes, elas ficaram muito animadas, deram muitas opiniões sobre roupas. Era a primeira vez que muitas delas entrariam em um teatro. Elas queriam decidir tudo, desde como seria o cabelo até os brincos e maquiagens. A participante Joelma relatou que queria ficar bem linda, queria uma maquiagem linda para arrasar. Essa questão de estar bem bonita para a apresentação é uma preocupação sempre presente nas mães, elas querem que esteja tudo lindo e bem arrumado, preocupam-se com os mínimos detalhes.

A dança é um conteúdo que vem contribuindo para que as cuidadoras percebam seu corpo (um corpo que precisa de cuidados), seus movimentos, suas possibilidades e seus limites. A percepção dessa contribuição da dança fica evidente quando a entrevistada Aylma explicita: "A gente sente vontade de se arrumar. Quando a gente vai dançar, quer colocar uma roupa bonita, quer se sentir bonita, mesmo não sendo. Eu tô me sentindo bem comigo mesma".

A escolha do conteúdo dança certamente foi importante nesse processo de desenvolvimento dos sujeitos, pois, como destacam Fonseca, Vecchi e Gama (2012), a dança proporciona o se movimentar com o outro, gerando uma maior relação com o seu corpo e com o corpo do outro, devido aos diversos sentimentos e emoções desencadeados pela dança com um parceiro. Os autores afirmam que avançar no conhecimento em dança significa se desenvolver também como pessoa.

Isso se mostrou presente no projeto, na medida em que as cuidadoras alegam que estão mais dispostas a ouvir o problema da outra e ajudar aquelas que têm dificuldade em determinada dança e situação de vida e também em relação aos filhos com deficiência. Estão presentes na aula o respeito com a outra, com o corpo da outra e também com o seu próprio corpo. A entrevistada Zenilda diz que:

Esse projeto aqui, da dança, uniu, gerou mais amizade, passamos a nos conhecer melhor, porque, com a dança, a convivência fica mais próxima. Bom seria se todas as mães participassem, porque tem gente que às vezes está tão cansado que não consegue nem dançar, o que é uma pena. Eu lamento. Eu queria que estivesse todo mundo aqui.

Essa troca de cuidado ocorre com todo o grupo, incluindo os(as) monitores(as) do projeto que são os responsáveis por planejar a aula, tendo sempre a preocupação em organizar atividades respeitando as diferenças e que sejam agradáveis e prazerosas para as cuidadoras.

$O$ vínculo com os(as) monitores(as) tem ocorrido de forma positiva. Notamos isso tanto nas avaliações como nas entrevistas. A entrevistada Aylma nos conta que há:

Um carinho incrível, um respeito muito grande com a gente. Fora do sério. 0 carinho é uma coisa que dá muita força pra gente, valoriza muito. As brincadeiras: em nenhum momento você vê assim alguém debochando ou desfazendo, fazendo com que a pessoa se sinta inferior, muito pelo contrário, colocando a gente pra cima, fazendo a gente se sentir bem [...].

Essa afetividade das cuidadoras com os(as) monitores(as) e vice-versa influencia não apenas o processo ensino-aprendizado, mas sobretudo cria um espaço em que, de modo diferente do que vivenciam cotidianamente, não são tratadas como inferiores por serem mães de pessoas com deficiência. Isso se torna uma chave de acesso importante para a autoestima e autoconfiança dessas mães.

Notamos em alguns momentos que, quando alguma participante tem dificuldade em um passo da dança, ela procura se sentar e só assistir à aula, por entender que não conseguirá 
realizar a atividade. Porém, quando um(a) monitor(a) se aproxima e a convida a realizar 0 passo junto com ele(a), a cuidadora se arrisca mais, pois sabe que tem alguém que está ao seu lado, apoiando e ajudando nas dificuldades. Com o tempo, as mães passaram a se descobrir também como pessoas com potencial para dançar.

O estudo indica que, ao longo das aulas, houve 0 avanço das participantes quanto à segurança em relação ao dançar. Fonseca, Vecchi e Gama (2012, p. 201) apontam que a dança, juntamente com o som da música, pode contribuir para reduzir a timidez e a dificuldade de interação no meio social, "[...] pois a dança exige comunhão e respeito com o outro, seja ele o parceiro com quem se dança, sejam os outros casais". A timidez foi uma questão que tivemos que trabalhar nas aulas, pois, no início do projeto, algumas cuidadoras não queriam participar das atividades devido à timidez por não saberem dançar.

Observamos que "o não saber dançar", "a inibição" e "a religiosidade" desestimulavam algumas mães, levando-as a não participar da aula. Os(as) monitores(as) estavam sempre ressaltando que ali era um espaço de aprendizado e todos estavam ali para aprender. Isso ajudou algumas mães a perceberem que não há problema em "errar", ou não "saber" dançar.

Com isso, a cada dia elas estavam mais seguras no "se-movimentar", visto que algumas das entrevistadas só tiveram contato com a dança ao participar do projeto. Essa situação pode ser evidenciada no relato da entrevistada Aylma: "Meu pai não deixava a gente dançar, ir ao baile, a lugar nenhum".

Trabalhamos também a liberdade de expressão, entendendo que o corpo fala por seus movimentos. Segundo Campeiz e Volp (2004), uma das dimensões da dança é a criatividade que deve ser valorizada, principalmente, numa proposta educativa que tem a dança como arte e que engloba aspectos criativos, estimulando os alunos a pensar e realizar movimentos novos, não se prendendo a movimentos preestabelecidos nem indicados pelo professor ou pela mídia.

Conforme Fiamoncini (2003), a "[...] arte implica modificar (criativamente) o existente para que ele chegue a ser outra coisa". Desse modo, entendemos arte como um meio pelo qual podemos questionar outras artes que nos são apresentadas e até desenvolvendo a nossa própria arte. Fiamoncini (2003) fala também sobre a importância do ambiente, que deve ser estimulante e favorável, permitindo a criação de novas ideias. Assim, foi importante no projeto o fato de se respeitar as diferentes capacidades das mães durante as aulas.

Outro aspecto destacado pelas cuidadoras foi o envolvimento dos professores e monitores com as aulas, o que é evidenciado na seguinte fala da entrevistada Welida:

\footnotetext{
[...] a maioria das mães está vendo isso aqui, estão dançando, mas não veem como uma coisa qualquer, elas levam a sério e, como a gente vê que vocês também estão levando a sério, a gente está tendo orgulho do grupo, porque os monitores mostraram isso para a gente, um trabalho sério, que não estão preparando de qualquer jeito.
}

Nesse sentido, o projeto propiciou às participantes a oportunidade de experimentar as danças e o seu dançar, não negando o conhecimento da técnica, no entanto compreendendo que, com base na técnica aprendida, cada um tem elementos para criar a sua "arte". Esse momento de criação/adaptação dos passos é fundamental para a aprendizagem. Assim, elas participavam mais da aula, pois não tinham a obrigação de imitar o professor ou de 
serem exímias executoras quanto a técnicas das diversas ${ }^{5}$ formas de dança que Ihes foram apresentadas.

\section{CONSIDERAÇÕES FINAIS}

O estudo realizado revela que o espaço/tempo de práticas dançantes que as cuidadoras encontraram no projeto "Cuidadores que dançam" configurou-se como algo que vai para além do entretenimento, pois, na avaliação das participantes, esse tem sido um lugar de redescoberta de si, de seu corpo, o que teria sido difícil experienciar não fosse seu ingresso no projeto.

As cuidadoras relataram que a criação desse projeto mudou significativamente suas vidas, demonstrando o quanto era bom estar ali, além de dizerem que ficavam aguardando a semana inteira pelo dia em que ocorreria a aula de dança. Afirmaram ainda que um dia só era pouco, que o projeto deveria atender em mais dias da semana.

As participantes revelaram que não dispõem de tempo para cuidar de si, uma vez que se dedicam ao cuidado dos filhos ou irmãos com deficiência, principalmente aquelas pertencentes aos estratos sociais de baixa renda. Portanto, cabe salientar a importância da criação de projetos voltados para cuidadores, de preferência que aconteçam simultaneamente ao atendimento do familiar com deficiência, em clínicas, espaços da comunidade ou em projetos sociais similares ao do Laefa.

O fato de realizar uma atividade, a dança, na qual não precisavam estar preocupadas em cuidar dos filhos foi significativo para o desenvolvimento das participantes, não só no aprendizado corporal e aquisição de conhecimentos em dança, pois, gradativamente, elas foram se percebendo como mulheres com uma identidade própria e não apenas como a mãe de fulano. ${ }^{6}$

Em seus depoimentos, as participantes da pesquisa demonstraram reconhecer que podem realizar outras tarefas além de ser cuidadoras, por exemplo, dançar. Assim, o projeto se tornou um lugar de partilha, de escuta sensível, de encontro consigo e com as outras cuidadoras e, principalmente, de manifestação corporal.

Em relação ao ressignificar a dança, identificamos que o projeto possibilitou às cuidadoras a oportunidade de dançar e recriar seus passos sem deixar de lado os aspectos técnicos da dança. Mas, como cada pessoa tem o seu próprio modo de dançar, esse gestual ia dando forma a um movimentar muito particular.

\section{REFERÊNCIAS}

BADINTER, Elisabeth. Um amor conquistado: o mito do amor materno. Tradução de Waltensir Dutra. Rio de Janeiro: Nova Fronteira, 1985.

BARDIN, Laurence. Análise de conteúdo. Lisboa: Edições 70, 2009.

BOFF, Leonardo. Saber cuidar: ética do humano, compaixão pela terra. Petrópolis, RJ: Vozes, 2011.

BRITO, Angela Maria Waked de; DESSEN, Maria Auxiliadora. Crianças surdas e suas famílias: um panorama geral. Psicologia: Reflexão e Crítica v.12, n.2, p.429-455, 1999.

5 No projeto as mães puderam ter contato com as diversas formas das danças sociais de salão (bolero, valsa, xote, baião etc.), danças populares do Brasil e de outros países (carimbó, dança do ventre, la cumbia etc.)

6 No início do projeto, as cuidadoras costumavam se apresentar como a mãe de fulano e não com o seu próprio nome. 
BUSCAGLIA, Leo. Os deficientes e seus pais. 2. ed. Rio de Janeiro: Record, 1993.

CAMPEIZ, Edvânia Conceição Fernandes Silva; VOLP, Catia Mary. Dança criativa: a qualidade da experiência subjetiva. Motriz, v.10, n.3, p. 167-172, 2004.

CASTILHO, Normandia Cristian Gilles. Identidade. In: GONZÁLEZ, Fernando Jaime; FENSTERSEIFER, Paulo Evaldo (Org.). Dicionário crítico de educação física. ljuí: Unijuí, 2005. p. 231-232.

D'ÁVILA, Sande Maria Gurgel. Relações de gênero no cotidiano familiar. Fortaleza, 2003.

Disponível em: <http://www.xxcbed.ufc.br/arqs/gt1/gt1_47.pdf>. Acesso em: 11 jul. 2016.

FIAMONCINI, Luciana. Dança na educação: a busca de elementos na arte e na estética. Pensar a Prática, v. 6, p. 59-72, jul./jun.2003.

FONSECA, Cristina Costa; VECCHI, Rodrigo Luiz; GAMA, Eliane Florêncio. A influência da dança de salão na percepção corporal. Motriz, v.18, n.1, p.200-207, 2012.

GIL, Antônio Carlos. Métodos e técnicas de pesquisa social. São Paulo: Atlas, 1999.

LAMB, Michael; BILLINGS, Lisa Laumann. Fathers of Children with Special Needs. In: LAMB, Michael (Org.). The role of the father in child development. New York: John Wiley, 1997. p. 179-190.

MELO, Cristiane Ker de; ANTUNES, Priscilla de Cesaro; SCHNEIDER, Maria Dênis. Cuida(do) corpo: experimentações acerca do "cuidar de si". In: SILVA, Ana Marcia; DAMIANI, lara Regina (Org.). Práticas corporais: experiências em educação física para uma formação humana.

Florianópolis: Nauemblu Ciência e Arte, 2005. v. 3, p.61-80.

MELO, José Pereira de. Consciência corporal. In: GONZÁLEZ, Fernando Jaime; FENSTERSEIFER, Paulo Evaldo (Org.). Dicionário crítico de educação física. ljuí: Unijuí, 2005. p. 175-176.

MOURA, Leonice; VALÉRIO, Naiana. A família da criança deficiente. Caderno de PósGraduação em Distúrbios do Desenvolvimento, v. 3, n. 1, p. 47-51, 2003.

NEVES, José Luis. Pesquisa qualitativa: características, usos e posibilidades. Cadernos de pesquisa em Administração, v.1, n.3, 1996. Disponível em: <http://www.regeusp.com.br/ arquivos/C03-art06.pdf>. Acesso em: 11 jul. 2016.

NUNES, Célia Cristina; SILVA, Nancy Capretz Batista da; AIELLO, Ana Lúcia Rossito. As contribuições do papel do pai e do irmão do indivíduo com necessidades especiais na visão sistêmica da família. Psicologia: teoria e pesquisa, v. 24, n.1, p.37-44, 2008.

PINTO, Nádia Maria da Silva. A dança promovendo a melhoria da qualidade de vida das pessoas da terceira idade. 2008. 42 f. Monografia (Licenciatura em Educação Física) Faculdades Integradas de Itapetinga, Itapetinga, 2008.

SOUZA, Maria Inez Galvão. Arte, cultura e sociedade: uma rede intrigante para algumas reflexões sobre a dança. In: ENCONTRO FLUMINENSE DE EDUCAÇÃO FÍSICA ESCOLAR, 8. 2004. Anais...Niteroi, 2004. p. 356-362.

WELTER, Ivânia et al. Gênero, maternidade e deficiência: representação da diversidade. Revista Textos e Contextos, v. 7, n. 1, p. 98-119, jan./jun. 2008. 
Apoio: PROEX/UFES

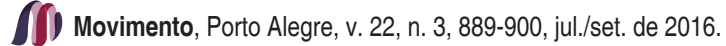

